\section{Research Square}

Preprints are preliminary reports that have not undergone peer review.

They should not be considered conclusive, used to inform clinical practice, or referenced by the media as validated information.

\title{
Analytical Performances of the Point-of-Care BIOSYNEX COVID-19 Ag BSS for the Detection of SARS-CoV-2 Nucleocapsid Protein in Nasopharyngeal Swabs: A Prospective Field Evaluation During the COVID-19 Third Wave in France
}

\author{
Fréderic Fitoussi \\ Centre Cardiologique du Nord \\ Serge Tonen-Wolyec \\ University of Kisangani \\ Natalio Awaida \\ Laboratoire Paris XV \\ Raphael Dupont \\ Centre Cardiologique du Nord \\ Laurent Belec ( $\square$ laurent.belec@aphp.fr) \\ Université de Paris https://orcid.org/0000-0002-5001-0405
}

Research

Keywords: COVID-19, Rapid diagnostic test, Antigen, N nucleocapsid protein, France.

Posted Date: May 24th, 2021

DOI: https://doi.org/10.21203/rs.3.rs-519746/v1

License: (9) (1) This work is licensed under a Creative Commons Attribution 4.0 International License. Read Full License 


\section{Abstract}

Background: Evaluating the accuracy and reliability of rapid diagnostic testing kits is crucial for surveillance and diagnosis of SARS-CoV-2 infections in general population. The aim of the study was to assess the analytical performances of the antigen-rapid diagnosis test (Ag-RDT) BIOSYNEX COVID-19 Ag BSS (Biosynex Swiss SA, Freiburg, Switzerland), targeting the SARS-CoV-2 N nucleocapsid protein, for the diagnosis of COVID-19, by reference to real-time RT-PCR (rtRT-PCR).

Methods: A total 967 adults living in Paris region were prospectively included during the third wave of the COVID-19 epidemic in France. Paired nasopharyngeal flocked swabs were collected at the same timepoint from persons aged $\geq 18$ years receiving testing for SARS-CoV-2, at two private laboratories.

Results: Overall, the Ag-RDT showed high sensitivity, specificity, PPV and NPV of $81.8 \%, 99.6 \%, 96.6 \%$ and $97.5 \%$, respectively, as well as high or almost perfect agreement (97.0\%), reliability assessed by Cohen's K coefficient (0.87), and accuracy assessed by Youden's J index (81.6\%) to detect SARS-CoV-2. The analytical performances of the Ag-RDT remained high in the event of significant viral excretion (i.e., $\mathrm{N}$ gene $\mathrm{C}_{\mathrm{t}}$ values $\leq 33$ by reference rtRT-PCR), while the sensitivity of the Ag-RDT dropped to $55.2 \%$ with low or very low viral shedding $\left(C_{t}>33\right)$.

Conclusions: The Ag-RDT BIOSYNEX COVID-19 Ag BSS showed high specificity and sufficient sensitivity for the detection of SARS-CoV-2. This test is a promising potential easy diagnostic tool, especially in situations of symptomatic COVID-19 and/or proven contagiousness.

\section{Introduction}

The Coronavirus disease 2019 (COVID-19) pandemic continues to spread across the world. The effective isolation and early treatment of patients infected by the severe acute respiratory syndrome coronavirus 2 (SARS-CoV-2) require rapid, simple and accurate diagnostic tools.

While currently-recommended nucleic acid amplification tests (NAAT), such as real-time reverse transcription polymerase chain reaction (rtRT-PCR) assays, remain the gold standard cornerstone for the diagnosis of SARS-CoV-2 infection [1, 2], immunological methods can also be used to detect viral antigens [2-4]. Indeed, performing rtRT-PCR is expensive, time-consuming, and requires special equipment and qualified operators. Faster, cheaper, and easier to use alternative tools could be represented by novel point-of-care antigen-detecting rapid diagnostic tests (Ag-RDT) [3]. Ag-RDT relies on direct detection of SARSCoV-2 viral proteins produced by replicating virus in nasal swabs and other respiratory secretions, often the virus $\mathrm{N}$ nucleocapsid protein, preferred because of its relative abundance and conserved structure, or other viral proteins such as the spike protein [4]. Most Ag-RDTs use sandwich catching by anti-SARS-CoV-2 monoclonal antibodies to detect viral antigens in the simple-to-use lateral flow immunoassay format allowing results in $<30$ minutes. Around 180 Ag-RDTs for SARS-CoV-2 infection are currently commercially available or in development [5]. However, there is significant variability reported with respect to their diagnostic performances and a lack of external validation for many of the available tests, which still require clinical validation [6-9].

Our study aimed to evaluate in the field the Ag-RDT BIOSYNEX COVID-19 Ag BSS (Biosynex Swiss SA, Freiburg, Switzerland; reference SW40006) for the diagnosis of COVID-19 using prospectively collected samples from adults living in the Paris region during the third wave of the COVID-19 epidemic in France. The results of this test were compared with qualitative and quantitative results obtained in parallel using rtRT-PCR as a reference test.

\section{Material And Methods}

Rapid antigen test. The Ag-RDT BIOSYNEX COVID-19 Ag BSS is a rapid qualitative membrane-based immunochromatographic test that uses highly sensitive monoclonal antibodies to detect the SARS-CoV-2 N nucleocapsid protein in nasopharyngeal secretions sample. The test includes a reaction membrane, and three buffers (sample, reagent and absorbent). The reagent buffer contains colloidal gold particles conjugated to monoclonal antibodies directed against the SARS-CoV-2 N protein; the reaction membrane also contains secondary antibodies directed against the $\mathrm{N}$ protein. The test strip is placed inside a plastic cassette. The test was performed according to manufacturer instruction by mixing nasopharyngeal secretions with $300 \mu \mathrm{L}$ of dilution buffer in a tube. After, one minute, 4 drops were added in the appropriate well. When the nasopharyngeal secretions are added to the sample well, crossing the strip, the dry conjugates of the reagent buffer are solubilized, allowing the conjugate to migrate with the sample and to react with the anti-SARS-CoV-2 antibodies immobilized on the membrane. If SARS-CoV-2 antigens are present in the sample, the complexes between the anti-SARS-CoV-2 conjugate and the virus are captured by anti-SARS-CoV-2 monoclonal antibodies specific to the test line area $(T)$. The absence of a $T$ line suggests a negative result. To serve as a procedural control, a red line appears in the control line area (C), indicating that the correct volume of sample has been added and that the membrane has played its role. Visual interpretation of results is performed $15 \mathrm{~min}$ after.

Study population and procedures. Paired nasopharyngeal flocked swabs were collected at the same timepoint from persons aged $\geq 18$ years receiving testing for SARS-CoV-2, at two private laboratories (site A: Centre Cardiologique du Nord, Saint-Denis, France; site B: Laboratoire Paris XV, Paris, France) during the third wave of the COVID-19 epidemic (March and April 2021). The sites offered SARS-CoV-2 testing to anyone in the community who wanted testing for suspected COVID-19, travel, as a pre-operative assessment, as a contact-case exposure of an individual infected with SARS-CoV-2 or as control of SARS-CoV-2 infection in the 30 days preceding. A questionnaire capturing demographic information (sex and age), reasons for testing and current and past-14-day symptoms for symptomatic patients was administered to all participants. Suggestive symptoms of COVID-19 were headache, fatigue, fever, or upper or lower respiratory symptoms. Asymptomatic individuals were defined as those not reporting any of these symptoms. Inclusion criteria were aged more than 18 years and agreement to undergo two concurrent nasopharyngeal swabs for rtRT-PCR and Ag-RDT. Thus, at both sites, a health care professional first collected nasopharyngeal secretions in one nostril, using the swab provided in the BIOSYNEX COVID-19 Ag BSS kit, immediately followed by a nasopharyngeal swab for rtRT-PCR. Covid-19 antigen rapid testing was immediately carried out on-site using the Ag-RDT according to the manufacturer's instructions. The other nasopharyngeal swabs were stored in physiological serum $(\mathrm{NaCl} 0.9 \%)(1000 \mu \mathrm{L})$ at $+4^{\circ} \mathrm{C}$ and analyzed within $24-48$ hours by the reference rtRT-PCR. 
Reference multiplex molecular detection of SARS-CoV-2. Nucleic acid extraction was performed from $300 \mu \mathrm{L}$ elution volume of nasopharyngeal flocked swab sample, using EX3600 extractor (Liferiver \& Shanghai ZJ Bio-Tech Co.), according to the manufacturer's instructions, and finally eluted in $50 \mu \mathrm{L}$ (final volume). SARS CoV-2 was detected in $5 \mu \mathrm{L}$ of extracted RNA using the multiplex real-time PCR Novel Coronavirus (2019-nCoV) Real-Time Multiplex RT-PCR Kit (Detection for 3 Genes) (Liferiver \& Shanghai ZJ Bio-Tech Co., Ltd, Shanghai, China), which constituted the reference multiplex rtRT-PCR for SARS-CoV-2 RNA detection. This assay can simultaneously detect 3 coronavirus target genes, including the SARS-like (including SARS-CoV-2, SARS-CoV, bat SARS-like coronavirus) conserved region of envelope protein gene (E), RNA-dependent RNA polymerase gene (ORF1ab of RdRP gene) and nucleocapsid protein gene (N), using reverse transcription followed by real-time PCR, providing individual cycle threshold $\left(\mathrm{C}_{t}\right)$ values for each target gene. Real-time PCR was carried out with CFX96 ${ }^{\text {TM }}$ Real-Time PCR Detection System (Bio-Rad Laboratories, Hercules, CA, USA), according to the manufacturer's instructions. The experiment and result interpretation were carried out according to the manufacturer's protocol. According to the manufacturer's instructions, samples showing an exponential growth curve and $\mathrm{Ct}$ value $\leq 41$ were considered positive. $A$ unique $C_{t}$ value $>41$ was considered negative.

Statistical analyses. Data were entered into an Excel database and analyzed using IBM ${ }^{\circledR}$ SPSS ${ }^{\circledR}$ Statistics 20 software (IBM, SPSS Inc, Armonk, New York, USA). Medians were calculated for quantitative variables. The results were presented along with their $95 \%$ confidence interval (Cl) using the Wilson score bounds for categorical variables [10]. Comparisons of frequencies between positive and negative results of Ag-RDT and rtRT-PCR testing between sites and all other variables were computed using the Pearson's Chi-square test or Fisher's exact test according to their validity conditions. The results of SARS-CoV-2 RNA detection by the multiplex rtRT-PCR were used as the reference standard to estimate the sensitivity and specificity of the study Ag-RDT, with corresponding $95 \% \mathrm{Cl}$. The concordance between study Ag-RDT and multiplex molecular detection of SARS-CoV-2 RNA was assessed by percent agreement corresponding to the observed proportion of identical results between Ag-RDT compared to rtRT-PCR detection. The reliability between the study Ag-RDT and the multiplex molecular detection of SARS-CoV-2 RNA was estimated by Cohen's $\mathrm{K}$ coefficient [11], and the degree of agreement was determined as ranked by Landlis and Koch [12]. The accuracy of the study Ag-RDT to correctly diagnose SARS-CoV-2 infection was estimated by Youden's $\mathrm{J}$ index $(\mathrm{J}=\mathrm{sensitivity}+$ specificity -1$)$ [13]. Positive predive values (PPV) and negative predictive values (NPV) were calculated according to Bayes's formulae, by considering the official reported prevalence of SARS-CoV-2-RNA positivity in symptomatic patients in Paris's area, France, on 12th April 2021, e.g. around the peak of the third wave epidemic in France (Santé publique France 2021; https://www.santepubliquefrance.fr/ ).

Ethics statement. The study was used as a clinical evaluation of the continuous quality improvement program and COVID-19 management measures performance evaluation, according to the national law on the accreditation of medical biology laboratories [14]. The dataset was completely anonymous and did not contain any identifiable personal health information.

\section{Results}

Paired nasopharyngeal respiratory swabs were collected from 967 persons, including 741 from site A and 226 from site B (Table 1). Participants ranged in age from 18 to 95 years (median = 34 years). The sex ratio of the study population was 0.94 . The main reasons for testing were air travel (35.6\%), contact-case exposure of an individual infected with SARS-CoV-2 (35.1\%), suspected COVID-19 ( $n=212,21.9 \%)$, pre-operative assessment (4.4\%) and control of SARS-CoV-2 infection in the 30 days preceding (3.0\%). At the time of testing, the majority $(722,74.7 \%)$ of participants were asymptomatic. A total of 245 (25.3\%) participants reported at least one COVID-19-compatible symptom, including 212 suspected COVID-19 cases, 29 (8.5\%) contact-cases, 3 (0.9\%) travelers, and 1 (3.0\%) patient with recent past-history of COVID-19. Among symptomatic patients, the median time of symptom duration before sampling was 4 days (range, 0-20 days). All comparisons between positive and negative results of Ag-RDT and rtRT-PCR testing between sites and all other variables did not reach statistical significance (not shown).

The vast majority [(114/124 (91.9\%)] of positive results appeared within the first five minutes, and frequently [(31/124 (25.0\%\%)] within one minute. Test results and main performances characteristics of the Ag-RDT BIOSYNEX COVID-19 Ag BSS compared with the reference rtRT-PCR in the study population according to COVID-19-compatible symptoms are depicted in Table 2. Using rtRT-PCR as the standard, three false-positive BIOSYNEX COVID-19 Ag BSS test results occurred, among specimens from asymptomatic $(n=2)$ or symptomatic $(n=1)$ participants. Among 148 rtRT-PCR positive results, 27 (18.2\%) were falsenegative BIOSYNEX COVID-19 Ag BSS test results (23 in specimens from asymptomatic persons and 4 in specimens from asymptomatic persons). Overall, the Ag-RDT BIOSYNEX COVID-19 Ag BSS showed high sensitivity, specificity, PPV and NPV of $81.8 \%, 99.6 \%, 96.6 \%$ and $97.5 \%$, respectively. Testing among asymptomatic participants indicated the following for the Ag-RDT BIOSYNEX COVID-19 Ag BSS (with rtRT-PCR as the standard): sensitivity, 79.4\%; specificity, 99.7\%; PPV, 97.3\%; and NPV, 97.2\% (Table 2); among symptomatic persons, sensitivity was 95.0\%; specificity, 99.4\%; PPV, 95.6\%; and NPV, 96.3\%. For participants who were within 7 days of symptom onset, the Ag-RDT BIOSYNEX COVID-19 Ag BSS sensitivity was 96.6\%, specificity, 99.4\%, PPV, $95.7 \%$, and NPV, $99.4 \%$.

The analytical results according to the level of viral excretion assessed by the $\mathrm{N}$ gene $\mathrm{C}_{\mathrm{t}}$ values by the reference rtRT-PCR are shown in Table 3 . Overall, the AgRDT BIOSYNEX COVID-19 Ag BSS showed high or almost perfect agreement (97.0\%), reliability assessed by Cohen's $\mathrm{K}$ coefficient (0.87), and accuracy assessed by Youden's $\mathrm{J}$ index $(81.6 \%)$ to detect SARS-CoV-2. These analytical performances were further stratified according to the cycle threshold $\left(\mathrm{C}_{t}\right)$ values of the $\mathrm{N}$ gene detected by reference rtRT-PCR considering $C_{t}$-related criteria of very high $\left(C_{t} \leq 20\right)$ and high $\left(C_{t} \leq 33\right)$ SARS-CoV-2 RNA excretion. Indeed, viral loads with $C_{t}>33$ are considered to be low and correspond to moderate or very low viral excretion [15-18]. Conversely, samples with $C_{t} \leq 33$ have a significant SARS-CoV-2 viral load, as in individuals symptomatic for COVID-19 or contagious. $C_{t}$ values $\leq 20$ indicate very high viral shedding [16-18]. There were two distinct situations. In the event of significant viral loads (high or very high) in real-time PCR $\left(\mathrm{C}_{\mathrm{t}} \leq 33\right)$, the Ag-RDT SBIOSYNEX COVID-19 Ag BSS showed excellent analytical performances, with sensitivities between $83.3 \%$ and $100.0 \%$, specificities of $99.8 \%$, PPV between $98.3 \%$ and $98.6 \%$ and NPV between $97.7 \%$ and $100.0 \%$. In the event of low or very low viral loads $\left(C_{t}>33\right)$, the sensitivity of the Ag-RDT BIOSYNEX COVID-19 Ag BSS showed reduced analytical performances with $55.2 \%$ sensitivity, while its specificity remained high (98.8\%). 


\section{Discussion}

We herein evaluated the analytical performances of the novel point-of-care Ag-RDT BIOSYNEX COVID-19 Ag BSS by reference to multiplex rtRT-PCR for SARSCoV-2 RNA detection as the gold standard in a real-life community setting. In this evaluation, the sensitivity of the Ag-RDT BIOSYNEX COVID-19 Ag BSS was lower among specimens from asymptomatic persons (79.4\%) than among specimens from symptomatic persons (95.0\%). Specificity (>99.0\%) was high in specimens from both asymptomatic and symptomatic groups. The prevalence of having SARS-CoV-2 RNA-positive rt-RT-PCR results in this population was relatively high (12.8\% overall; $6.5 \%$ for asymptomatic participants and $31.4 \%$ for symptomatic participants), and the estimated PPVs and NPVs of the Ag-RDT BIOSYNEX COVID-19 Ag BSS were elevated in all groups of participants. However, administering the Ag-RDT in lower prevalence settings will likely result in lower predictive values. In the event of significant viral excretion (i.e., $\mathrm{N}$ gene $\mathrm{C}_{\mathrm{t}}$ values below 33 by reference rtRT-PCR), the Ag-RDT RDT BIOSYNEX COVID-19 Ag BSS showed high sensitivity (from 83.3-100.0\%) and specificity (>99.0\%) for SARS-CoV-2 RNA detection, with excellent concordance, reliability and accuracy with the reference multiplex rtRT-PCR, and PPVs and NPVs above $97.0 \%$. The sensitivity of the study Ag-RDT dropped however to $55.2 \%$ with low or very low viral shedding $\left(C_{t}>33\right)$. Taken together, these observations demonstrate that the Ag-RDT BIOSYNEX COVID-19 Ag BSS harbored high analytical performances, which makes it suitable to be used as point-of-care Ag-RDT in various hospital and non-hospital settings where a rapid diagnosis of SARS-CoV2 is necessary. Although less sensitive than RT-PCR, the Ag-RDT BIOSYNEX COVID-19 Ag BSS could be beneficial due to its rapid results, ease of use, and independence from existing laboratory structures. Testing criteria focusing on patients with typical symptoms in their early symptomatic period onset could further increase its diagnostic value.

In the present series, the sensitivity of the Ag-RDT BIOSYNEX COVID-19 Ag BSS was $81.8 \%$ overall, and the positive detection rate was comparable to the rtRTPCR in the majority $(88.2 \%)$ of patients with $C_{t} \leq 33$. Twelve of $14(85.7 \%)$ false-negative subjects with significant viral excretion $\left(C_{t} \leq 33\right)$ were

asymptomatic, although conflicting evidence exists regarding the relationship between symptom severity and viral shedding [19]. In the present large series, false-positive test results were rarely observed, providing $99.6 \%$-specificity in our study, which exceeded the performance recommended by the World Health Organization (WHO) [20]. Some false-positive results have been reported in other antigen tests [21-23]. While definitive proof is lacking, possible causes for the false-positives include the high viscosity of specimens and interference of human antibodies [24].

Finally, the Ag-RDT RDT BIOSYNEX COVID-19 Ag BSS fulfilled the current WHO's recommendations for a screening Ag-RTD stating that, at minimum, Ag-RDTs would need to correctly identify significantly more cases than they would miss (sensitivity $\geq 80 \%$ ) and would have very high specificity ( $\geq 97-100 \%$ ) [20]. Furthermore, analytical performances of comparable order as those of our study Ag-RDT were previously reported for some Ag-RDTs in lateral flow immunoassay format [7, 9, 21, 25-35], while several studies have reported much lower sensitivity levels contrasting with always high specificity [3, 36-41]. For example, a comparable Ag-RDT such as the novel COVID-VIRO ${ }^{\circledR}$ from AAZ (Boulogne Billancourt, France) showed a sensitivity of $96.7 \%$ and a specificity of $100 \%$ in a real-life community setting [31]. In addition, the Ag-RDT RDT BIOSYNEX COVID-19 Ag BSS fulfilled also the current recommendations of the French High Authority of Health (Haute Autorité de santé, Saint-Denis, France) for a screening Ag-RTD stating that, at minimum, Ag-RDTs would need to correctly identify significant proportions of symptomatic patients (sensitivity $\geq 80 \%$ ) as well as asymptomatic individuals (sensitivity $\geq 50 \%$ ) and would have very high specificity $(\geq 90 \%)[42]$.

We analyzed our results according to the estimated viral load in SARS-CoV-2 in the samples. There is an ongoing debate regarding the $C_{t}$ value corresponding to the threshold of infectivity (i.e., patient considered as contagious) [16]. Indeed, there is a trend to a natural gradual decrease of the SARS-CoV-2 RNA load in the nasopharyngeal samples overtime during the course of infection, at the origin of varying levels of contagiousness [43]. La Scola et al. found that patients with $C_{t}$ value $>33$ are not contagious because of the low number of positive cultures [44]. This is consistent with the Centers for Disease Control and Prevention (CDC) recommendations, which propose a $C_{t}$ value of 33 as a surrogate of contagiousness [15], with $C_{t}$ values $\leq 20$ indicating very high viral shedding [16-18]. In our series, we have stratified the nasopharyngeal samples according to the level of viral excretion, indirectly evaluated by the value of the $\mathrm{C}_{t}$ of the $\mathrm{N}$ gene according to the reference rtRT-PCR, in order to calculate the performance of the study Ag-RDT at different proposed cut-offs for contagiousness.

Our results clearly show that the analytical performances of the Ag-RDT BIOSYNEX COVID-19 Ag BSS were much better in the event of a high viral load, i.e., in the case of significant viral excretion. These observations demonstrate the interest of the Ag-RDT BIOSYNEX COVID-19 Ag BSS as a rapid rule-in test for COVID-19 with samples at high viral load, in symptomatic patients for example, and point caution with its use as a singular rule-out test especially in the setting of samples with lower viral loads.

The SARS-CoV-2 RNA positive subpopulation of our clinical samples collection was characterized by a wide range of $C_{t}$-values with medium and low $C_{t}$-values dominating. This allowed the calculation of sensitivity and specificity values with higher relevance for clinical practice. The $C_{t}$-dependent evaluation showed very good sensitivity for highly and moderately SARS-CoV-2 positive samples $\left(C_{t} \leq 33\right)$. In contrast, the sensitivity of the assay with specimens containing only a limited viral load was lower. Thus, COVID-19 infection would not be detected in patients in the very early or late phase of the infection typically associated with a low viral load. However, differentiation between contagious and non-contagious individuals may be possible with this assay. Samples with $\mathrm{C}_{\mathrm{t}}$-values $>$ 33 usually do not allow culturing of the virus indicating low infectivity $[16,44]$. Such individuals may be regarded as non-contagious despite carrying low virus loads. This differentiation of individuals may be of particular importance for the decision on access to susceptible individuals, for example in nursing homes or in many other medical circumstances. Similar observations of dramatic decrease of sensitivity of Ag-RDT for SARS-CoV-2 antigen detection at $\mathrm{C}_{t}$ thresholds around 25-33 were previously reported [7,38,45,46], confirming that Ag-RDTs were most effective to identify RT-PCR positive symptomatic patients or asymptomatic subjects with high viral loads in their respiratory secretions (i.e., $\mathrm{C}_{\mathrm{t}}$ values $\leq 33$ ).

In our study, the accuracy of the Ag-RDT BIOSYNEX COVID-19 Ag BSS was estimated by the percent positive agreement and not sensitivity. Since the agreement is measured relative to an RT-PCR test, which may be imperfect itself [47]. Compounding this uncertainty, we have largely exceeded the minimum 
sample size of 30 positive cases that is required to apply for evaluation [8], which made it possible to restrict the confidence intervals of the evaluated variables.

Our study has several strengths. All samples were collected from one nasopharynx with flocked swabs, which is optimal for the evaluation of Ag-RDT clinical performances in our study. The Ag-RDT was performed in parallel to RT-PCR. The study population included a variety of situations outside the hospital setting with a majority of young adults without comorbidities, who mostly had typical and mild COVID-19 symptoms when being symptomatic. This currently describes the majority of SARS-CoV-2 infected individuals, and an important group for limiting community transmission. The findings in this investigation are also subject to limitations. Participants might have inadvertently reported common nonspecific symptoms as COVID-19-compatible symptoms. This investigation evaluated the BIOSYNEX COVID-19 Ag BSS antigen test, and the results presented here cannot be generalized to other agencies-authorized SARSCoV-2 antigen tests. Finally, the BIOSYNEX COVID-19 Ag BSS antigen test characteristics might be different depending on whether an individual had been previously tested positive.

\section{Conclusion}

The Ag-RDT BIOSYNEX COVID-19 Ag BSS showed very high specificity and sufficient sensitivity for the detection of SARS-CoV-2. Given the simple procedures and shorter turnaround time involved with this test, it is a promising option as an alternative diagnostic modality especially in situations of symptomatic COVID-19 and/or proven contagiousness. The test can also be offered to test asymptomatic individuals in many situations of potential exposure to SARSCoV-2 and in mass screening at the population level.

\section{Abbreviations}

Ag-RDT: Antigen-detecting rapid diagnostic tests

CDC: Centers for Disease Control and Prevention

COVID-19: Coronavirus disease 2019

NAAT: nucleic acid amplification test

rtRT-PCR: real-time reverse transcription polymerase chain reaction

SARS-CoV-2: Severe acute respiratory syndrome coronavirus 2

WHO: World Health Organization

\section{Declarations}

Ethics approval and consent to participate. The study has been approved by the local scientific committee of Parc de l'Innovation, Strasbourg, France, and informed participants consent was obtained.

Consent for publication. All authors approved the submission of the manuscript for publication.

Availability of data and materials. The data is available and can be used for the academic or research purposes.

Competing interest. The authors report no conflicts of interest. The authors alone are responsible for the content and the writing of the paper.

Funding. No grant was received from the test manufacturers.

Contributions. FF, RD and LB have conceived and designed the research; FF, NA and RD performed the experiments and STW the statistical analyses; RD, STW and LB analyzed the results and drafted the manuscript.

Acknowledgments. The authors thank all nurses and staff at the Centre Cardiologique du Nord, Saint-Denis, and Laboratoire Paris XV, Paris, as well as the patients for their willingness to participate in the study. We are grateful to Biosynex, Strasbourg, France, for providing for the tests for the study. Dr. Serge Tonen-Wolyec was recipient of ERASMUS program between the University of Kisangani, Democratic Republic of the Congo, and the University of Liège, Belgium.

\section{References}

1. Smithgall MC, Dowlatshahi M, Spitalnik SL, Hod EA, Rai AJ. Types of Assays for SARS-CoV-2 Testing: A Review. Lab Med. 2020;51:e59-65.

2. Rai P, Kumar BK, Deekshit VK, Karunasagar I, Karunasagar I. Detection technologies and recent developments in the diagnosis of COVID-19 infection. Appl Microbiol Biotechnol. 2021 Jan;105(2):441-55.

3. Dinnes J, Deeks JJ, Adriano A, Berhane S, Davenport C, Dittrich S, Emperador D, Takwoingi Y, Cunningham J, Beese S, Dretzke J, Ferrante di Ruffano L, Harris IM, Price MJ, Taylor-Phillips S, Hooft L, Leeflang MM, Spijker R, Van den Bruel A. Cochrane COVID-19 Diagnostic Test Accuracy Group., Rapid, pointof-care antigen and molecular-based tests for diagnosis of SARS-CoV-2 infection. Cochrane Database Syst Rev. 2020 Aug;26:8:CD013705.

4. Li D, Li J. Immunologic testing for SARS-CoV-2 infection from the antigen perspective. J Clin Microbiol. 2020 Dec 14:JCM.02160-20. 
5. Find. Sars-CoV-2 Diagnostics Pipeline. 2020. Available online: https://www.finddx.org/covid-19/pipeline/ (accessed on 03 May 2021).

6. Mattiuzzi C, Henry B, Lippi G. Making sense of rapid antigen testing in SARS-CoV-2 diagnostics. Diagnosis (Berl). 2021 Apr 20. doi: 10.1515/dx-20210034.

7. Favresse J, Gillot C, Oliveira M, Cadrobbi J, Elsen M, Eucher C, Laffineur K, Rosseels C, Van Eeckhoudt S, Nicolas JB, Morimont L, Dogné JM, Douxfils J. Head-to-Head Comparison of Rapid and Automated Antigen Detection Tests for the Diagnosis of SARS-CoV-2 Infection. J Clin Med. 2021 Jan 13;10(2):E265.

8. Fitzpatrick MC, Pandey A, Wells CR, Sah P, Galvani AP. Buyer beware: inflated claims of sensitivity for rapid COVID-19 tests. Lancet. 2021 Jan;397(10268) (2):24-5

9. Schildgen V, Demuth S, Lüsebrink J, Schildgen O. Limits and Opportunities of SARS-CoV-2 Antigen Rapid Tests: An Experienced-Based Perspective. Pathogens. 2021 Jan 5;10(1):E38.

10. Newcombe RG. Two-sided confidence intervals for the single proportion: comparison of 362 seven methods. Stat Med. 1998;17:857-72.

11. Cohen J. A coefficient of agreement for nominal scales. Educ Psychol Meas. 1960;20:37-46.

12. Landlis JR, Koch GG. The measurement of observer agreement for categorical data. Biometrics. 1977;33(1):159-74.

13. Youden WJ. Index for rating diagnostic tests. Cancer. 1950;3(1):32-5.

14. Journal Officiel de la République Française. Ordonnance $n^{\circ}$ 2010-49 du 13 janvier 2010 relative à la biologie médicale. Available at: https://www.legifrance.gouv.fr/jorf/id/JORFTEXT000021683301/ (last access 21 January 2021).

15. Centers for Disease Control and Prevention. Common Investigation Protocol for Investigating Suspected SARS-CoV-2 Reinfection. Available at: https://www.cdc.gov/coronavirus/2019-ncov/php/reinfection.html\#print (last access 03 May 2021).

16. Jefferson T, Spencer EA, Brassey J, Heneghan C. Viral cultures for COVID-19 infectious potential assessment - a systematic review. Clin Infect Dis. 2020 Dec 3:ciaa1764.

17. Société Française de Microbiologie (SFM). Avis du 25 septembre 2020 de la Société Française de Microbiologie (SFM) relatif à l'interprétation de la valeur de $\mathrm{C}_{\mathrm{t}}$ (estimation de la charge virale) obtenue en cas de RT-PCR SARS-CoV-2 positive sur les prélèvements cliniques réalisés à des fins diagnostiques ou de dépistage. Version 1 _ 25/09/2020. Available at: https://www.sfm-microbiologie.org/wp-content/uploads/2020/09/Avis-SFM-valeur-Ctexcre\%CC\%81tion-virale-_-Version-Finale-25092020.pdf (last access 03 May 2021).

18. Yu F, Yan L, Wang N, Yang S, Wang L, Tang Y, Gao G, Wang S, Ma C, Xie R, Wang F, Tan C, Zhu L, Guo Y, Zhang F. Quantitative Detection and Viral Load Analysis of SARS-CoV-2 in Infected Patients. Clin Infect Dis. 2020 Jul 28;71(15):793-798.

19. Magleby R, Westblade LF, Trzebucki A, Simon MS, Rajan M, Park J, Goyal P, Safford MM, Satlin MJ. Impact of SARS-CoV-2 viral load on risk of intubation and mortality among hospitalized patients with coronavirus disease 2019. Clin Infect Dis. 2020 Jun 30:ciaa851.

20. World Health Organization. Interim guidance. Antigen-detection in the diagnosis of SARS-CoV-2 infection using rapid immune-assays. 11 September 2020. Available at: file:///C:/Users/prbel/Downloads/WHO-2019-nCoV-Antigen_Detection-2020.1-eng\%20(1).pdf (lass access: 04 May 2021).

21. Chaimayo C, Kaewnaphan B, Tanlieng N, Athipanyasilp N, Sirijatuphat R, Chayakulkeeree M, Angkasekwinai N, Sutthent R, Puangpunngam N, Tharmviboonsri T, Pongraweewan O, Chuthapisith S, Sirivatanauksorn Y, Kantakamalakul W, Horthongkham N. Rapid SARS-CoV-2 antigen detection assay in comparison with real-time RT-PCR assay for laboratory diagnosis of COVID-19 in Thailand. Virol J. 2020 Nov 13;17(1):177.

22. Tanimoto T, Matsumura M, Tada S, Fujita S, Ueno S, Hamai K, Omoto T, Maeda H, Nishisaka T, Ishikawa N. Need for a high-specificity test for confirming weakly positive result in an immunochromatographic SARS-CoV-2-specific antigen test: A case report. J Microbiol Immunol Infect. 2020 Dec 1; S16841182(20)30272-3.

23. Corman VM, Haage VC, Bleicker T, Schmidt ML, Mühlemann B, Zuchowski M, Jo WK, Tscheak P, Möncke-Buchner E, Müller MA, Krumbholz A, Drexler JF, Drosten C. Comparison of seven commercial SARS-CoV-2 rapid point-of-care antigen tests: a single-centre laboratory evaluation study. Lancet Microbe. 2021 Apr 7. doi:10.1016/S2666-5247(21)00056-2.

24. U.S. Food and Drug Administration. Potential for false positive results with antigen tests for rapid detection of SARS-CoV-2 - Letter to clinical laboratory staff and health care providers, https://www.fda.gov/medical-devices/letters-health-care-providers/potential-false-positive-results-antigen-tests-rapiddetection-sars-cov-2-letter-clinical-laboratory (lass access: 04 May 2021).

25. Cerutti F, Burdino E, Milia MG, Allice T, Gregori G, Bruzzone B, Ghisetti V. Urgent need of rapid tests for SARS CoV-2 antigen detection: Evaluation of the SDBiosensor antigen test for SARS-CoV-2. J Clin Virol. 2020 Nov;132:104654.

26. Diao B, Wen K, Zhang J, Chen J, Han C, Chen Y, Wang S, Deng G, Zhou H, Wu Y. Accuracy of a nucleocapsid protein antigen rapid test in the diagnosis of SARS-CoV-2 infection. Clin Microbiol Infect. 2020 Oct;5:1198-743X. :(20)30611-X..

27. Linares M, Pérez-Tanoira R, Carrero A, Romanyk J, Pérez-García F, Gómez-Herruz P, Arroyo T, Cuadros J. Panbio antigen rapid test is reliable to diagnose SARS-CoV-2 infection in the first 7 days after the onset of symptoms. J Clin Virol. 2020 Dec;133:104659.

28. Toptan T, Eckermann L, Pfeiffer AE, Hoehl S, Ciesek S, Drosten C, Corman VM. Evaluation of a SARS-CoV-2 rapid antigen test: Potential to help reduce community spread? J Clin Virol. 2020 Dec 5;135:104713.

29. Weitzel T, Legarraga P, Iruretagoyena M, Pizarro G, Vollrath V, Araos R, Munita JM, Porte L. Comparative evaluation of four rapid SARS-CoV-2 antigen detection tests using universal transport medium. Travel Med Infect Dis. 2020 Dec 2;39:101942.

30. Berger A, Nsoga MTN, Perez-Rodriguez FJ, Aad YA, Sattonnet-Roche P, Gayet-Ageron A, Jaksic C, Torriani G, Boehm E, Kronig I, Sacks JA, de Vos M, Bausch FJ, Chappuis F, Renzoni A, Kaiser L, Schibler M, Eckerle I. Diagnostic accuracy of two commercial SARS-CoV-2 antigen-detecting rapid tests at the point of care in community-based testing centers. PLoS One. 2021 Mar;31(3):e0248921. 16(. 
31. Courtellemont L, Guinard J, Guillaume C, Giaché S, Rzepecki V, Seve A, Gubavu C, Baud K, Le Helloco C, Cassuto GN, Pialoux G, Hocqueloux L, Prazuck T. High performance of a novel antigen detection test on nasopharyngeal specimens for diagnosing SARS-CoV-2 infection. J Med Virol. 2021 May;93(5):3152-7.

32. Mboumba Bouassa RS, Veyer D, Péré H, Bélec L. Analytical performances of the point-of-care SIENNA ${ }^{\text {TM }}$ COVID-19 Antigen Rapid Test for the detection of SARS-CoV-2 nucleocapsid protein in nasopharyngeal swabs: A prospective evaluation during the COVID-19 second wave in France. Int J Infect Dis. 2021 Mar 18;106:8-12.

33. Landaas ET, Storm ML, Tollånes MC, Barlinn R, Kran AB, Bragstad K, Christensen A, Andreassen T. Diagnostic performance of a SARS-CoV-2 rapid antigen test in a large, Norwegian cohort. J Clin Virol. 2021 Apr;137:104789.

34. Matsuda EM, de Campos IB, de Oliveira IP, Colpas DR, Carmo AMDS, Brígido LFM. Field evaluation of COVID-19 antigen tests versus RNA based detection: Potential lower sensitivity compensated by immediate results, technical simplicity, and low cost. J Med Virol. 2021 Mar 31. doi:10.1002/jmv.26985.

35. Takeuchi Y, Akashi Y, Kato D, Kuwahara M, Muramatsu S, Ueda A, Notake S, Nakamura K, Ishikawa H, Suzuki H. The evaluation of a newly developed antigen test (QuickNavi-COVID19 Ag) for SARS-CoV-2: A prospective observational study in Japan. J Infect Chemother. 2021 Jun;27(6):890-4.

36. Albert E, Torres I, Bueno F, Huntley D, Molla E, Fernández-Fuentes M, Martínez M, Poujois S, Forqué L, Valdivia A, Solano de la Asunción C, Ferrer J, Colomina J, Navarro D. Field evaluation of a rapid antigen test (Panbio COVID-19 Ag Rapid Test Device) for COVID-19 diagnosis in primary healthcare centres. Clin Microbiol Infect. 2020 Nov 13:S1198-743X(20)30697-2.

37. Scohy A, Anantharajah A, Bodéus M, Kabamba-Mukadi B, Verroken A, Rodriguez-Villalobos H. Low performance of rapid antigen detection test as frontline testing for COVID-19 diagnosis. J Clin Virol. 2020 Aug;129:104455.

38. Yamayoshi S, Sakai-Tagawa Y, Koga M, Akasaka O, Nakachi I, Koh H, Maeda K, Adachi E, Saito M, Nagai H, Ikeuchi K, Ogura T, Baba R, Fujita K, Fukui T, Ito F, Hattori SI, Yamamoto K, Nakamoto T, Furusawa Y, Yasuhara A, Ujie M, Yamada S, Ito M, Mitsuya H, Omagari N, Yotsuyanagi H, Iwatsuki-Horimoto K, Imai M, Kawaoka Y. Comparison of Rapid Antigen Tests for COVID-19. Viruses. 2020 Dec 10;12(12):1420.

39. Osterman A, Baldauf HM, Eletreby M, Wettengel JM, Afridi SQ, Fuchs T, Holzmann E, Maier A, Döring J, Grzimek-Koschewa N, Muenchhoff M, Protzer U, Kaderali L, Keppler OT. Evaluation of two rapid antigen tests to detect SARS-CoV-2 in a hospital setting. Med Microbiol Immunol. 2021 Jan 16. doi:10.1007/s00430-020-00698-8.

40. Torres I, Poujois S, Albert E, Colomina J, Navarro D. Evaluation of a rapid antigen test (Panbio COVID-19 Ag rapid test device) for SARS-CoV-2 detection in asymptomatic close contacts of COVID-19 patients. Clin Microbiol Infect. 2021 Jan 6:S1198-743X(20)30782-5.

41. Torres I, Poujois S, Albert E, Álvarez G, Colomina J, Navarro D. Point-of-care evaluation of a rapid antigen test (CLINITEST ${ }^{\circledR}$ Rapid COVID-19 Antigen Test) for diagnosis of SARS-CoV-2 infection in symptomatic and asymptomatic individuals. J Infect. 2021 May;82(5):e11-2.

42. Haute Autorité de santé. Saint-Denis, France, 8 octobre 2020. Revue rapide sur les tests de détection antigénique du virus SARS-CoV-2. Available at: file://C:/Users/prbel/Downloads/synthese_tests_antigeniques_vd\%20(1).pdf I.

43. Zou L, Ruan F, Huang M, Liang L, Huang H, Hong Z, Yu J, Kang M, Song Y, Xia J, Guo Q, Song T, He J, Yen HL, Peiris M, Wu J. SARS-CoV-2 Viral Load in Upper Respiratory Specimens of Infected Patients. N Engl J Med. 2020 Mar;19(12):1177-9. 382(.

44. La Scola B, Le Bideau M, Andreani J, Hoang VT, Grimaldier C, Colson P, Gautret P, Raoult D. Viral RNA load as determined by cell culture as a management tool for discharge of SARS-CoV-2 patients from infectious disease wards. Eur J Clin Microbiol Infect Dis. 2020 Jun;39(6):1059-61.

45. Baro B, Rodo P, Ouchi D, Bordoy AE, Saya Amaro EN, Salsench SV, Molinos S, Alemany A, Ubals M, Corbacho-Monné M, Millat-Martinez P, Marks M, Clotet B, Prat N, Estrada O, Vilar M, Ara J, Vall-Mayans M, G-Beiras C, Bassat Q, Blanco I, Mitjà O. Performance characteristics of five antigen-detecting rapid diagnostic test (Ag-RDT) for SARS-CoV-2 asymptomatic infection: a head-to-head benchmark comparison. J Infect. 2021 Apr 18:S0163-4453(21)00191-2.

46. Krüttgen A, Cornelissen CG, Dreher M, Hornef MW, Imöhl M, Kleines M. Comparison of the SARS-CoV-2 Rapid antigen test to the real star Sars-CoV-2 RT PCR kit. J Virol Methods. 2021 Feb;288:114024.

47. Miller TE, Garcia Beltran WF, Bard AZ, Gogakos T, Anahtar MN, Astudillo MG, Yang D, Thierauf J, Fisch AS, Mahowald GK, Fitzpatrick MJ, Nardi V, Feldman J, Hauser BM, Caradonna TM, Marble HD, Ritterhouse LL, Turbett SE, Batten J, Georgantas NZ, Alter G, Schmidt AG, Harris JB, Gelfand JA, Poznansky MC, Bernstein BE, Louis DN, Dighe A, Charles RC, Ryan ET, Branda JA, Pierce VM, Murali MR, lafrate AJ, Rosenberg ES, Lennerz JK. Clinical sensitivity and interpretation of PCR and serological COVID-19 diagnostics for patients presenting to the hospital. FASEB J. 2020 Oct;34(10):13877-84.

\section{Tables}

Table 1. Characteristics of persons providing paired upper respiratory swab ( $\mathrm{n}=967)$ for real-time reverse transcription-polymerase chain reaction ( $r$ RT-PCR) testing and BIOSYNEX COVID-19 Ag BSS rapid diagnostic testing for SARS-CoV-2 at two private laboratory sites, by test results, Paris, France, spring 2021. 


\begin{tabular}{|c|c|c|c|c|c|}
\hline \multirow[b]{2}{*}{ Characteristics } & \multirow[b]{2}{*}{$\begin{array}{l}\text { To number } \\
\text { of persons } \\
\text { (column \%) }\end{array}$} & \multicolumn{4}{|c|}{ Number of persons (row\%) } \\
\hline & & $\begin{array}{l}\text { rRT-PCR- } \\
\text { negative }\end{array}$ & $\begin{array}{l}\text { rRT-PCR- } \\
\text { positive }\end{array}$ & $\begin{array}{l}\text { Antigen- } \\
\text { negative }\end{array}$ & $\begin{array}{l}\text { Antigen- } \\
\text { positive }\end{array}$ \\
\hline Total & $967(100)$ & $819(84.7)$ & $148(15.3)$ & $844(87.3)$ & $123(12.7)$ \\
\hline $\begin{array}{l}\text { Testing site } \\
\text { A } \\
\text { B }\end{array}$ & $\begin{array}{l}741(74.6) \\
226(25.4)\end{array}$ & $\begin{array}{l}633(85.4) \\
186(82.4)\end{array}$ & $\begin{array}{r}108(14.6) \\
40(17.6)\end{array}$ & $\begin{array}{l}651(87.9) \\
193(85.4)\end{array}$ & $\begin{array}{l}90(12.1) \\
33(14.6)\end{array}$ \\
\hline $\begin{array}{l}\text { Sex } \\
\text { Female } \\
\text { Male }\end{array}$ & $\begin{array}{l}498(51.5) \\
469(48.5)\end{array}$ & $\begin{array}{l}429(86.2) \\
390(83.2)\end{array}$ & $\begin{array}{l}69(13.8) \\
79(16.8)\end{array}$ & $\begin{array}{l}438(88.0) \\
406(86.6)\end{array}$ & $\begin{array}{l}60(12.0) \\
63(13.4)\end{array}$ \\
\hline $\begin{array}{l}\text { Age group, years } \\
18-49 \\
50-64 \\
\geq 65 \\
\text { Median age (range) }\end{array}$ & $\begin{array}{l}740(76.4) \\
157(16.3) \\
70(7.3) \\
34(18-83)\end{array}$ & $\begin{array}{r}629(85.0) \\
129(82.2) \\
61(87.1) \\
34(18-83)\end{array}$ & $\begin{array}{r}111(15.0) \\
28(17.8) \\
9(12.9) \\
32(18-82)\end{array}$ & $\begin{array}{r}647(87.4) \\
133(84.7) \\
64(91.4) \\
34(18-83)\end{array}$ & $\begin{array}{r}93(12.6) \\
24(15.3) \\
6(8.6) \\
37(18-82)\end{array}$ \\
\hline $\begin{array}{l}\text { Current symptoms } \\
\geq 1 \\
\text { None }\end{array}$ & $\begin{array}{l}245(25.3) \\
722(74.7)\end{array}$ & $\begin{array}{l}165(67.4) \\
654(90.6)\end{array}$ & $\begin{array}{l}80(32.6) \\
68(9.4)\end{array}$ & $\begin{array}{l}168(68.6) \\
676(93.6)\end{array}$ & $\begin{array}{l}77(31.4) \\
46 \quad(6.4)\end{array}$ \\
\hline $\begin{array}{l}\text { Days from the onset } \\
0-3 \\
4-7 \\
>7 \\
\leq 7 \\
\text { Median (range) }\end{array}$ & $\begin{array}{r}107(43.3) \\
122(49.8) \\
16(6.9) \\
229(93.1) \\
4(0-20)\end{array}$ & $\begin{array}{r}38(35.5) \\
48(39.4) \\
11(68.7) \\
86(37.6) \\
4(0-20)\end{array}$ & $\begin{array}{r}69(64.5) \\
74(60.6) \\
5(31.3) \\
143(62.4) \\
3(0-15)\end{array}$ & $\begin{array}{r}41(38.3) \\
69(56.6) \\
12(75.0) \\
110(48.0) \\
4(0-20)\end{array}$ & $\begin{array}{r}66(61.7) \\
53(43.4) \\
4(25.0) \\
119(52.0) \\
3(0-10)\end{array}$ \\
\hline $\begin{array}{l}\text { Positive test results in past } \\
\text { Yes } \\
\text { No/Unknown }\end{array}$ & $\begin{array}{l}\text { days } \\
29(3.0) \\
938(97.0)\end{array}$ & $\begin{array}{r}20(68.9) \\
799(85.2)\end{array}$ & $\begin{array}{r}9(31.1) \\
139(14.8)\end{array}$ & $\begin{array}{r}21(72.4) \\
823(87.7)\end{array}$ & $\begin{array}{r}8(27.6) \\
115(12.3)\end{array}$ \\
\hline $\begin{array}{l}\text { Exposure to a diagnosed C } \\
\text { Yes } \\
\text { No/Unknown }\end{array}$ & $\begin{array}{l}\text { VID-19 case (ca } \\
340(35.1) \\
627(64.9)\end{array}$ & $\begin{array}{l}\text { se-contact) } \\
282(82.9) \\
537(85.7)\end{array}$ & $\begin{array}{l}58(17.1) \\
90(14.3)\end{array}$ & $\begin{array}{l}293(86.2) \\
551(87.9)\end{array}$ & $\begin{array}{l}47(13.8) \\
76(12.1)\end{array}$ \\
\hline $\begin{array}{l}\text { Travel } \\
\text { Yes } \\
\text { No }\end{array}$ & $\begin{array}{l}344(35.6) \\
623(64.4)\end{array}$ & $\begin{array}{l}330(95.9) \\
489(78.5)\end{array}$ & $\begin{array}{r}14(4.1) \\
134(21.5)\end{array}$ & $\begin{array}{l}337(98.0) \\
507(81.4)\end{array}$ & $\begin{array}{r}7(2.0) \\
116(18.6)\end{array}$ \\
\hline $\begin{array}{l}\text { Preoperative assessment } \\
\text { Yes } \\
\text { No }\end{array}$ & $\begin{array}{r}42(4.4) \\
925(95.6)\end{array}$ & $\begin{array}{r}38(90.5) \\
781(84.4)\end{array}$ & $\begin{array}{r}4(9.5) \\
144(15.6)\end{array}$ & $\begin{array}{r}40(95.2) \\
804(86.9)\end{array}$ & $\begin{array}{r}2(2.8) \\
121(13.1)\end{array}$ \\
\hline
\end{tabular}

Table 2. Test results and performances characteristics of the BIOSYNEX COVID-19 Ag BSS rapid diagnostic test compared with real-time reverse transcriptionpolymerase chain reaction (rRT-PCR) for SARS-CoV-2 testing among asymptomatic and symptomatic persons at two private laboratory sites, by test results, Paris, France, spring 2021. 
rRT-PCR (number of test, \%)

\begin{tabular}{|c|c|c|c|}
\hline \multirow[b]{2}{*}{ Results and performances } & \\
\hline & Negative & Positive & Total \\
\hline \multicolumn{4}{|c|}{ BIOSYNEX COVID-19 Ag BSS results } \\
\hline Positive & $3(0.3)$ & $121(12.5)$ & $124(12.8)$ \\
\hline Negative & $816(84.4)$ & $27(2.8)$ & $843(87.2)$ \\
\hline Total & $819(78.8)$ & $148(21.2)$ & $967(100)$ \\
\hline \multicolumn{4}{|l|}{ Asymptomatic $(\mathrm{n}=722)$} \\
\hline Positive & $2(0.3)$ & $45(4.2)$ & $47(6.5)$ \\
\hline Negative & $652(90.3)$ & $23(5.2)$ & $675(95.5)$ \\
\hline Total & $654(90.6)$ & $68(9.4)$ & $722(100)$ \\
\hline \multicolumn{4}{|c|}{ Symptomatic $(\unrhd 1$ symptom $)(\mathrm{n}=245)$} \\
\hline Positive & $1(0.4)$ & $76(31.0)$ & $77(31.4)$ \\
\hline Negative & $164(67.0)$ & $4(1.6)$ & $168(68.6)$ \\
\hline Total & $165(67.4)$ & $80(32.6)$ & $245(100)$ \\
\hline \multicolumn{4}{|c|}{ Symptomatic $(\leq 7$ days from symptom onset) $(\mathrm{n}=229)$} \\
\hline Positive & $1(0.5)$ & $72(31.4)$ & $73(31.9)$ \\
\hline Negative & $153(66.8)$ & $3(1.3)$ & $156(68.1)$ \\
\hline Total & $154(67.3)$ & $75(32.7)$ & $229(100)$ \\
\hline \multirow{2}{*}{\multicolumn{4}{|c|}{$\begin{array}{l}\text { BIOSYNEX COVID-19 Ag BSS performances }(\%, 95 \% \mathrm{CI}) \\
\text { All participants }\end{array}$}} \\
\hline & & \multirow{4}{*}{\multicolumn{2}{|c|}{$\begin{array}{l}81.8(79.2-84.1) \\
99.6(98.9-99.8) \\
96.6(95.3-97.6) \\
97.5(96.3-98.3)\end{array}$}} \\
\hline Specificity & & & \\
\hline $\mathrm{PPV}^{i}$ & & & \\
\hline $\mathrm{NPV}^{z}$ & & & \\
\hline \multicolumn{4}{|l|}{ Asymptomatic } \\
\hline Sensitivity & & \multirow{2}{*}{\multicolumn{2}{|c|}{$\begin{array}{l}79.4(76.3-82.2) \\
99.7(98.9-99.9)\end{array}$}} \\
\hline Specificity & & & \\
\hline PPV & & \multicolumn{2}{|c|}{$97.3(95.8-98.2)$} \\
\hline NPV & & \multicolumn{2}{|c|}{$97.2(95.7-98.2)$} \\
\hline \multicolumn{4}{|l|}{ Symptomatic } \\
\hline Sensitivity & & \multirow{2}{*}{\multicolumn{2}{|c|}{$\begin{array}{l}95.0(91.5-97.1) \\
99.4(97.4-99.9)\end{array}$}} \\
\hline Specificity & & & \\
\hline PPV & & \multicolumn{2}{|c|}{$95.6(92.2-97.5)$} \\
\hline NPV & & \multicolumn{2}{|c|}{$99.3(97.2-99.8)$} \\
\hline \multicolumn{4}{|c|}{ Symptomatic ( $\leq 7$ days from onset) } \\
\hline Sensitivity & & \multirow{4}{*}{\multicolumn{2}{|c|}{$\begin{array}{l}96.0(92.6-97.9) \\
99.4(97.3-99.9) \\
95.7(92.2-97.7) \\
99.4(97.3-99.9)\end{array}$}} \\
\hline Specificity & & & \\
\hline PPV & & & \\
\hline NPV & & & \\
\hline
\end{tabular}

${ }^{£}$ PPV and NPV were calculated according to the Bayes's formulae, by taking into account the official reported prevalence of SARS-CoV-2-RNA positivity in COVID-19-suspected patients in Paris's area, France, of 12.2\% on $12^{\text {th }}$ April 2021 [Santé publique France 2021; https://www.santepubliquefrance.fr/].

Cl: Confidence interval; NVP: Negative predictive value; PPV: Positive predictive value

Table 3. Analytical performances of the BIOSYNEX COVID-19 Ag BSS rapid diagnostic test for the qualitative detection of the N protein of SARS-CoV-2 using 967 prospectively collected nasopharyngeal swab samples by reference rRT-PCR ${ }^{\#}$, according to their $\mathrm{N}_{\text {gene }} \mathrm{C}_{\mathrm{t}}$ values. 
BIOSYNEX COVID-19 Ag BSS

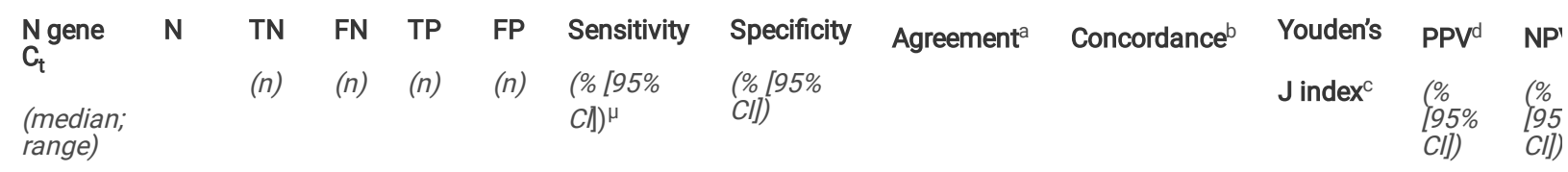

\begin{tabular}{|c|c|c|c|c|c|c|c|c|c|c|c|c|}
\hline$\leq 20$ & $\begin{array}{l}17.9 \\
(13.9- \\
20.0)\end{array}$ & 35 & NA & 0 & 35 & NA & $\begin{array}{l}100(99.6 \\
-100)\end{array}$ & $\begin{array}{l}99.6(98.9 \\
-99.8)\end{array}$ & $\begin{array}{l}99.6(98.9 \\
-99.8)\end{array}$ & $\begin{array}{l}0.95(0.93- \\
0.96)\end{array}$ & $\begin{array}{l}99.6 \\
(98.9- \\
99.8))\end{array}$ & $\begin{array}{l}97.2 \\
(95.9 \\
-98.1)\end{array}$ \\
\hline
\end{tabular}

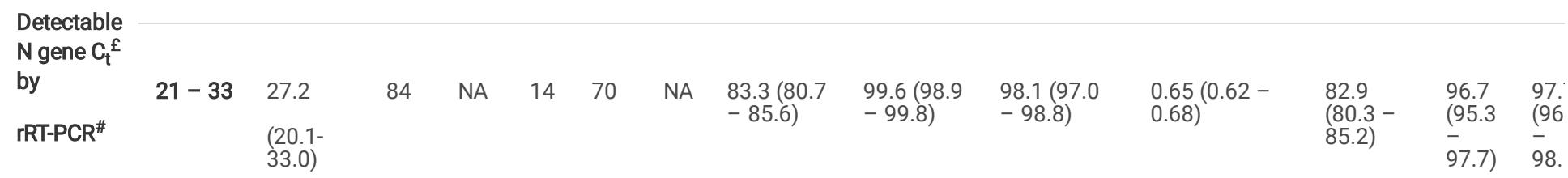

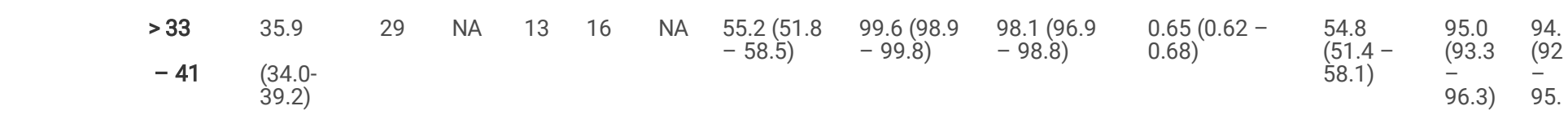

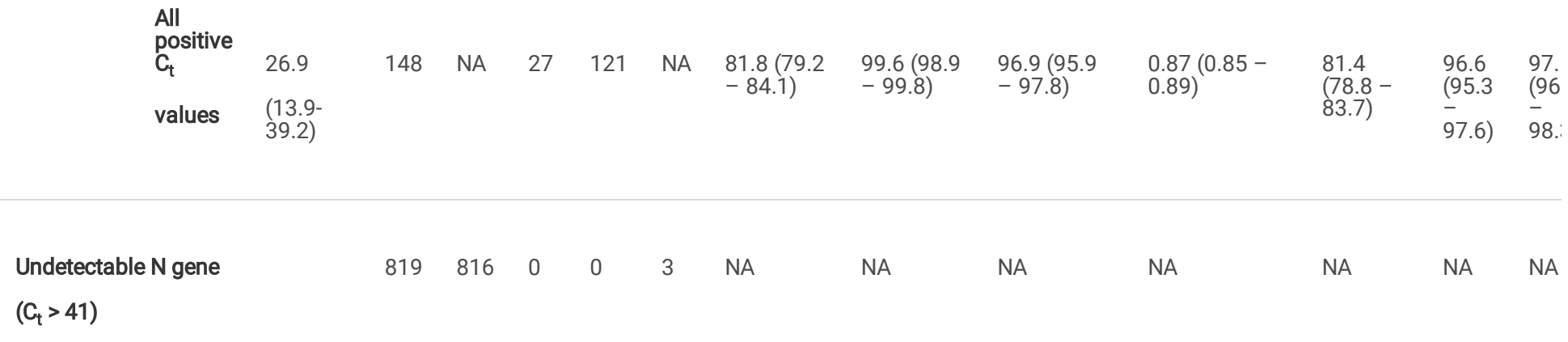

$\S$ Paired nasopharyngeal samples in each nostril were collected with a flocked swab for each volunteer patients by trained healthcare personnel (nurses, doctors or biologists). The collection of the two simultaneous samples was always carried out by the same operator. Molecular testing as well COVID-19 antigen detection were carried out on fresh samples;

${ }^{\text {a }}$ Agreement $=\mathrm{TP}+\mathrm{TN} / \mathrm{TP}+\mathrm{FP}+\mathrm{TN}+\mathrm{FN}$, expressed in percentage;

b The Cohen's k coefficient calculation was used to estimate the concordance [11] and interpreted according the Landis and Koch scale [12], as follows: < 0 as indicating no agreement, $0-0.20$ as slight, $0.21-0.40$ as fair, $0.41-0.60$ as moderate, $0.61-0.80$ as substantial, and $0.81-1$ as almost perfect concordance;

c The accuracy of the test BIOSYNEX COVID-19 Ag BSS to correctly diagnose SARS-CoV-2 infection was estimated by Youden's $\mathrm{J}$ index $(\mathrm{J}=$ sensitivity + specificity - 1) [13];

d PPV and NPV were calculated according to the Bayes's formulae, by taking into account the official reported prevalence of SARS-CoV-2-RNA positivity in COVID-19-suspected patients in Paris's area, France, of 12.2\% on $12^{\text {th }}$ April 2021 [Santé publique France 2021; https://www.santepubliquefrance.fr/];

$\mu 95 \%$ confidence intervals in brackets were calculated by using the Wilson score bounds;

${ }^{£}$ The $C_{t}$ values of $\mathrm{N}$ gene detection by the reference Liferiver rRT-PCR were used to classify nasopharyngeal samples according to their level of SARS-CoV-2 RNA excretion; $C_{t}$ of 20 and 33 were taken as thresholds of very high and high SARS-CoV-2 RNA excretion, respectively, as previously stated [15-18]; 
\# The CE IVD-marked Novel Coronavirus (2019-nCoV) Real Time Multiplex RT-PCR Kit (Detection for 3 Genes) (Liferiver \& Shanghai ZJ Bio-Tech Co., Ltd, Shanghai, China) constituted the reference multiplex rRT-PCR for SARS-CoV-2 RNA detection. This assay detects three target genes of SARS-CoV-2 (E, RdRP and $\mathrm{N}$ genes).

$C_{t}$ : Cycle threshold; FN: False negative; FP: False positive; NA: Not attributable; NPV: Negative predictive value; PPV: Positive predictive value; rRT-PCR: real-time reverse transcription-polymerase chain reaction; TP: True positive; TN: True negative 